\title{
The correlates of social capital and adherence to healthy lifestyle in patients with coronary heart disease
}

Jialie Fang ${ }^{1, *}$

Ji-Wei Wang ${ }^{2, *}$

Jiang $\mathrm{Li}^{3}$

Hua $\mathrm{Li}^{4}$

\section{Chunhai Shao ${ }^{5}$}

'Shanghai Jing'an District Center for Disease Control and Prevention, Shanghai, People's Republic of China; ${ }^{2}$ Key Lab of Health Technology Assessment of Ministry of Health, School of Public Health, Fudan University, Shanghai, People's Republic of China; ${ }^{3}$ Faculty of Health, University of Canberra, Canberra, Australian Capital Territory, Australia; ${ }^{4}$ Department of Cardiac Surgery, Zhongshan Hospital, Fudan University, Shanghai, People's Republic of China; ${ }^{5}$ Department of Nutrition, Huashan Hospital, Fudan University, Shanghai, People's Republic of China

*These authors contributed equally to this work
This article was published in the following Dove Press journal:

Patient Preference and Adherence

30 September 2017

Number of times this article has been viewed

Objective: To investigate the correlates of social capital and adherence to healthy lifestyle in patients with coronary heart disease (CHD).

Methods: This register-based, cross-sectional study consisted of individuals diagnosed with CHD at four community health service centers, Shanghai, China, between April and July 2016 $(n=609)$. The sociodemographic characteristics, social capital, adherence to physical activity, and nutrition data were obtained through face-to-face interviews. Social capital was assessed by social participation, social networking, social support, social trust, and sense of belonging. Physical activity and nutrition were measured with the Health-Promoting Lifestyle Profile II. The independent two-sample $t$-test and Pearson's correlations were used to analyze associations among variables. Hierarchical multiple regression models were used to evaluate effects of social capital on adherence to physical activity and nutrition.

Results: The average age of the sample was 60.87 (standard deviation [SD] =6.91), with 54.4\% being male and $45.6 \%$ female. The average score of physical activity and nutrition were 2.38 $(\mathrm{SD}=0.59)$ and $2.78(\mathrm{SD}=0.50)$, respectively. The final model significantly explained $28.9 \%$ of variance in physical activity $(F=34.96, P<0.001)$ and $30.5 \%$ of variance in nutrition $(F=37.73$, $P<0.001$ ). Most of the subdimensions of social capital were significantly associated with physical activity and nutrition, after controlling for marital status and education level.

Conclusion: The results suggested that social capital was the correlate of adherence to longterm healthy lifestyle, including physical activity and nutrition. These findings highlight the need to take into account social capital in developing intervention strategies to improve the adherence to the long-term healthy lifestyle for patients with CHD.

Keywords: social capital, adherence, healthy lifestyle, coronary heart disease

\section{Introduction}

Coronary heart disease (CHD) is a leading cause of death and disability worldwide. ${ }^{1}$ In contemporary China, there are more than one million deaths per year from CHD, which has become the number one killer. ${ }^{2}$ Because of the threat of high-risk recurrent CHD events, secondary prevention of CHD is crucial and cost-effective. ${ }^{3}$ Adherence to prescribed medicines and lifestyle recommendations is critical in the secondary prevention of CHD. ${ }^{4}$ The World Health Organization defines adherence to long-term therapies not only as the extent to of a person's behavior of taking medication, but also executing and following lifestyle changes, such as physical activity and nutrition, corresponding with agreed recommendations from a health care provider. ${ }^{5}$

Adherence has been focused on in most current published research studies. Poor adherence in CHD patients was associated with increased rehospitalization 
and mortality. ${ }^{6,7}$ However, individuals with CHD were no more likely to be adherent to a healthy lifestyle than people without these conditions. ${ }^{8}$ Complementing biomedical approaches to prevent and treat cardiovascular disease demonstrated the importance of behavioral factors and behavioral approaches to optimal management. ${ }^{9}$ Patients with CHD should be encouraged to do mild-to-moderate physical activity, such as regular walking, frequent recreational activities, or once-weekly sporting activities. ${ }^{10}$ However, the general rate of adherence to healthy lifestyle in patients with CHD is far from optimistic. ${ }^{11,12}$ Poor adherence to healthy lifestyle is a key public health problem of high prevalence, and important gaps in knowledge remain regarding its course, causes, and the best ways to improve it.

Social capital can be a useful tool in promoting adherence in patients with chronic diseases, ${ }^{13-16}$ as this consists of social networks that together with shared norms, values, and understandings enable participation within or among groups with homogenous characteristics, ${ }^{17}$ thereby improving the efficacy of society by facilitating coordinated actions for shared benefits. ${ }^{18}$ Social capital is often divided into structural and cognitive componets. ${ }^{19}$ The structural social capital refers to the externally observable behaviors and actions of actors within the network, eg, patterns of social participation, and the cognitive social capital refers to the relevant individual's values, attitudes, codes, and beliefs (including "trust" and "norms"). ${ }^{19-21}$ The structural and cognitive components could further be seen as the quantity (frequency) and quality (how the contacts are perceived) aspects of social networks. ${ }^{19}$ Moreover, social capital research often concerns the level of analysis - whether social capital is treated as an individuallevel attribute or as a community-level characteristic. ${ }^{22}$ Despite considerable disagreement with regard to conception and measurement of social capital, ${ }^{23,24}$ social capital theory has become prominent in public health research.

There are limited data on adherence in patients with CHD in China, especially regarding its associations with social capital. This study aims to investigate the association between social capital and adherence, including physical activity and nutrition, among patients with CHD. The findings may guide health professionals to design valid interventions to improve adherence to the healthy lifestyle in patients with CHD.

\section{Methods}

\section{Sample and setting}

Using a convenience sampling method, patients with CHD were recruited from four community health service centers in Shanghai, China, between April and July 2016. The criteria for study enrollment are: 1) being clinically diagnosed with CHD; 2) being able to read, write, and speak in Chinese; and 3) volunteering to participate in this study. Data were collected by the researcher and assistant registered nurses through face-to-face structured interviews in: 1) patients with coronary angiography in which at least 1 lesion had more than 50\% stenosis; 2) patients with stable angina pectoris; 3) patients with unstable angina pectoris; 4) patients with old myocardial infarction; 5) patients with acute myocardial infarction; 6) patients after percutaneous coronary intervention; 7) patients after surgery for coronary artery bypass grafting; 8) patients with ischemic cardiomyopathy; and 9) patients with asymptomatic coronary heart disease. The interviewers ask fixed questions in a consistent format. A total of 720 eligible patients were invited to participate, and 609 agreed to participate in the study, leading to a response rate of $84.6 \%$.

Ethical approval to conduct this study was granted by the Medical Research Ethics Committee of the Shanghai Jing'an District Center for Disease Control and Prevention, Shanghai, China (protocol number RB \#2015-07). A written informed consent was obtained from each patient.

\section{Instrument}

\section{Sociodemographic characteristics}

The sociodemographic characteristics included age, sex, marital status, and the highest educational level achieved.

\section{Social capital}

In this study, we developed a social capital instrument consisting of five different broad and multidimensional scales, namely, social participation, social networking, social support for structural social capital, social trust, and sense of belonging, to measure cognitive social capital. The construction of social capital scales was similar to Berry et al. ${ }^{25,26}$ These were typical subscales used in previous studies. ${ }^{27-30}$ All items were scored on a 5-point Likert scale (1 - never; 2 - rarely; 3 - sometimes; 4 - often; 5 - always). Mean scores of each subscale were obtained by calculating the subject's response. We computed Cronbach's alpha coefficient to check the internal consistency and reliability of each of the five social capital scales. All reliability estimates were higher than 0.85 . The subscales and the items are described below.

\section{Social participation}

Four items were used to assess social participation: participate in activities organized by the government department; participate in volunteer activities; participate in activities 
organized by social groups; and participate in recreational activities.

\section{Social networking}

Three items were used to assess social networking: be with family; be with friends; and be with neighbors.

\section{Social support}

Six items were used to assess social support: have common interests with others; you can get help from others when you need; feel the concern of others; someone will share his/her experience and fun in life; some will listen to my worries; and someone will listen to my opinions when deciding or discussing things.

\section{Social trust}

Three items were used to assess social support index: trust others; trust government; and trust social organizations.

\section{Sense of belonging}

Three items were used to assess sense of belonging: satisfied with the community environment; satisfied with community public facilities; and satisfied with community safety.

\section{Physical activity and nutrition}

Physical activity and nutrition were measured with the Health-Promoting Lifestyle Profile II (HPLP II). ${ }^{31}$ The HPLP II instrument consists of 52 items in six subdimensions: 1) Health responsibility, 9 items; 2) Physical activity, 8 items; 3) Nutrition, 9 items; 4) Spiritual growth, 9 items; 5) Interpersonal relations, 9 items; and 6) Stress management, 8 items. All items were scored on a 4-point Likert scale (1 - not at all; 2 - sometimes; 3 - often; 4 - always). In this study, the subdimensions of Physical activity and Nutrition were employed for measuring the physical activity and nutrition.

Mean scores of physical activity and nutrition were obtained by calculating the subject's response. Therefore, physical activity and nutrition score could range from 1 to 4 . A higher score indicates a greater level of health behaviors. Cronbach's $\alpha$ was 0.87 for physical activity and 0.81 for nutrition in the present study.

\section{Translation of the scales}

Two translators who were native speakers of Chinese language independently conducted forward translation of the Physical activity and Nutrition subdimension from the HPLP II from English to Chinese, and first and second forward translations was subsequently compiled to form a third translation. The third translation was backtranslated in English by a person unaware of the source document. A final version evolved through a series of discussions among principal investigator, researchers involved in project, and translators so as to resolve discrepancies in the translation. Permissions for translation were obtained from the developers of the HPLP II scale.

A pilot test was then conducted to assess the readability and comprehension of the questionnaire. Ten middle-aged women with CHD participated in the pilot test and were not subsequently included in the main study. After the pilot test, all the respondents were required to talk about whether they had any difficulties in understanding and completing the instrument; there was no respondent encounter the same hesitations, requests for clarification, or suggestions for different wording on this instrument.

\section{Statistical analysis}

Traditional sociodemographic characteristics [age, gender, marital status, and highest grade/education achieved] were initially examined using descriptive statistics. Pearson correlation, independent two-sample $t$-test, and $\chi^{2}$ analysis were used to examine bivariate relationships between sociodemographic variables, social capital, physical activity, and nutrition for continuous and categorical variables, respectively. Hierarchical multiple regression models were used to examine the relationship between social capital and adherence to physical activity and nutrition. A $p$-value $\leq 0.05$ was considered statistically significant. All statistical analyses were performed using the Statistical Package for the Social Sciences for Windows (Version 21.0; IBM Corporation, Armonk, NY, USA).

\section{Results \\ Sociodemographic characteristics of subjects}

The sociodemographic characteristics of the sample in the present study are shown in Table 1 . The average age of the sample was 60.87 (standard deviation [SD] =6.91), with $54.4 \%$ being male and $45.6 \%$ female. The majority of participants (89.7\%) were married, and 340 (52.5\%) participants were educated up to high school level or more.

\section{Descriptive statistics for physical activity, nutrition, and social capital}

As shown in Table 2, the average scores for physical activity and nutrition were $2.38(\mathrm{SD}=0.59)$ and $2.78(\mathrm{SD}=0.50)$, respectively. The average scores for social participation, 
Table I Sociodemographic characteristics of subjects $(\mathrm{N}=609)$

\begin{tabular}{llll}
\hline Characteristics & N & $\%$ & M \pm SD \\
\hline Gender & 331 & 54.35 & \\
$\quad$ Male & 278 & 45.65 & \\
$\quad$ Female & & & $60.87 \pm 6.91$ \\
Age, years & 238 & 39.08 & \\
$\quad<60$ & 371 & 60.92 & \\
$\quad \geq 60$ & & & \\
Education & 289 & 47.45 & \\
$\quad$ Middle school or less & 340 & 52.55 & \\
$\quad$ High school or more & & & \\
Marital status & 546 & 89.66 & \\
$\quad$ Married & 63 & 10.34 & \\
$\quad$ Single/widowed/divorced & 63 &
\end{tabular}

Abbreviations: M, mean; SD, standard deviation.

social networking, social support, social trust, and sense of belonging were 3.38 ( $\mathrm{SD}=0.90), 3.68(\mathrm{SD}=0.77)$, $3.58(\mathrm{SD}=0.66), 4.01(\mathrm{SD}=0.80)$, and $3.39(\mathrm{SD}=0.95)$, respectively.

\section{Differences in physical activity and nutrition by sociodemographic characteristics}

Table 3 shows differences in healthy lifestyles by demographic characteristics. Subjects who were married $(t=-3.55$, $p<0.001)$ and received higher education $(t=2.04, p<0.05)$ reported higher nutrition scores.

\section{Correlations between physical activity, nutrition, and social capital}

Correlations among the outcome variables (adherence to physical activity and nutrition) and explanatory factors (subdimensions of social capital) are also shown in Table 4. All variables were correlated significantly in a positive direction, and the Pearson correlation coefficients ranged from 0.30 to 0.71 .

Table 2 Descriptive statistics for physical activity, nutrition, and social capital

\begin{tabular}{lllll}
\hline Variables & $\begin{array}{l}\text { No of } \\
\text { items }\end{array}$ & $\begin{array}{l}\text { Possible range } \\
\text { of single item }\end{array}$ & M & SD \\
\hline Physical activity & 8 & $\mathrm{I}-4$ & 2.38 & 0.59 \\
Nutrition & 9 & $\mathrm{I}-4$ & 2.78 & 0.50 \\
Social participation & 4 & $\mathrm{I}-5$ & 3.38 & 0.90 \\
Social networking & 3 & $\mathrm{I}-5$ & 3.68 & 0.77 \\
Social support & 6 & $\mathrm{I}-5$ & 3.58 & 0.66 \\
Social trust & 3 & $\mathrm{I}-5$ & $4.0 \mathrm{I}$ & 0.80 \\
Sense of belonging & 3 & $\mathrm{I}-5$ & 3.39 & 0.95 \\
\hline
\end{tabular}

Abbreviations: $M$, mean; SD, standard deviation.
Table 3 Differences in physical activity and nutrition by sociodemographic characteristics ( $N=609)$

\begin{tabular}{|c|c|c|c|c|c|c|}
\hline \multirow[t]{2}{*}{ Variable } & \multicolumn{3}{|c|}{ Physical activity } & \multicolumn{3}{|c|}{ Nutrition } \\
\hline & $\mathbf{M}$ & SD & $\boldsymbol{t}$ & $\mathbf{M}$ & SD & $t$ \\
\hline Gender & & & 0.46 & & & -1.01 \\
\hline Male & 2.39 & 0.57 & & 2.76 & 0.51 & \\
\hline Female & 2.37 & 0.62 & & 2.80 & 0.50 & \\
\hline Age, years & & & -1.618 & & & 0.95 \\
\hline$<60$ & 2.33 & 0.60 & & 2.76 & 0.50 & \\
\hline$\geq 60$ & 2.41 & 0.59 & & 2.80 & 0.51 & \\
\hline Education & & & -1.55 & & & $-3.55^{*}$ \\
\hline Middle school or less & 2.34 & 0.59 & & 2.70 & 0.50 & \\
\hline High school or more & 2.41 & 0.59 & & 2.85 & 0.50 & \\
\hline Marital status & & & 0.983 & & & $2.04 * *$ \\
\hline Married & 2.39 & 0.59 & & 2.79 & 0.50 & \\
\hline Single/widowed/divorced & 2.31 & 0.62 & & 2.66 & 0.51 & \\
\hline
\end{tabular}

Notes: $* P<0.001 ; * * P<0.05$.

Abbreviations: $\mathrm{M}$, mean; $\mathrm{SD}$, standard deviation.

\section{Effects of social capital on physical activity and nutrition}

As shown in the above results, the statistically significant differences in nutrition by marital status and education level should be controlled to examine the effects of social capital on adherence to health behaviors among patients with CHD using hierarchical multiple regression models (Table 5). The overall model significantly explained $28.9 \%$ of variance in physical activity $(F=34.96, p<0.001)$ and $30.5 \%$ of variance in nutrition $(F=37.73, p<0.001)$. After controlling for the marital status and education level, the effects of subdimensions of social capital on physical activity and nutrition remained significant.

\section{Discussion}

The key findings of the study show that social networking and sense of belonging, and social support showed clear significant associations with physical activity and nutrition,

Table 4 The correlations of social capital, physical activity, and nutrition

\begin{tabular}{|c|c|c|c|c|c|c|c|}
\hline Variables & Cronbach's $\alpha$ & I & 2 & 3 & 4 & 5 & 6 \\
\hline Social capital & 0.93 & & & & & & \\
\hline I. Social participation & 0.85 & & & & & & \\
\hline 2. Social networking & 0.86 & 0.53 & & & & & \\
\hline 3. Social support & 0.90 & 0.57 & 0.53 & & & & \\
\hline 4. Social trust & 0.91 & 0.53 & 0.49 & 0.64 & & & \\
\hline 5. Sense of belonging & 0.94 & 0.37 & 0.30 & 0.58 & 0.52 & & \\
\hline \multicolumn{8}{|c|}{ Adherence } \\
\hline 6. Physical activity & 0.87 & 0.46 & 0.38 & $0.4 I$ & 0.45 & 0.35 & \\
\hline 7. Nutrition & 0.81 & 0.40 & 0.36 & 0.48 & 0.49 & 0.32 & 0.71 \\
\hline
\end{tabular}


Table 5 Hierarchical multiple regression for the effects of social capital on adherence to physical activity and nutrition

\begin{tabular}{|c|c|c|c|c|c|c|c|c|}
\hline \multirow[t]{2}{*}{ Predictors } & \multicolumn{4}{|c|}{ Physical activity } & \multicolumn{4}{|c|}{ Nutrition } \\
\hline & B & SE & $\beta$ & $t$ & B & SE & $\beta$ & $t$ \\
\hline \multicolumn{9}{|l|}{ Step I } \\
\hline Education & 0.07 & 0.05 & 0.06 & 1.55 & 0.14 & 0.04 & 0.14 & $3.56^{*}$ \\
\hline Married status & 0.08 & 0.08 & 0.04 & 0.98 & 0.14 & 0.07 & 0.08 & $2.05 * *$ \\
\hline$R^{2}$ & 0.01 & & & & 0.03 & & & \\
\hline$F$ & 1.69 & & & & $8.50^{*}$ & & & \\
\hline \multicolumn{9}{|l|}{ Step 2} \\
\hline Education & 0.02 & 0.04 & 0.02 & 0.58 & 0.05 & 0.04 & 0.05 & 1.56 \\
\hline Married status & 0.07 & 0.07 & 0.04 & 1.01 & 0.13 & 0.06 & 0.08 & $2.37^{* *}$ \\
\hline $\begin{array}{l}\text { Social } \\
\text { participation }\end{array}$ & 0.16 & 0.03 & 0.25 & $5.48^{*}$ & 0.06 & 0.25 & 0.11 & $2.42 * *$ \\
\hline $\begin{array}{l}\text { Social } \\
\text { networking }\end{array}$ & 0.08 & 0.03 & 0.10 & $2.39 * *$ & 0.03 & 0.03 & 0.05 & 1.20 \\
\hline Social support & 0.03 & 0.05 & 0.04 & 0.68 & 0.17 & 0.04 & 0.22 & $4.22^{*}$ \\
\hline Social trust & 0.04 & 0.04 & 0.18 & $3.78^{*}$ & 0.15 & 0.03 & 0.24 & $5.08 *$ \\
\hline $\begin{array}{l}\text { Sense of } \\
\text { belonging }\end{array}$ & 0.07 & 0.03 & 0.11 & $2.6 I^{* * * *}$ & 0.01 & 0.02 & 0.01 & 0.33 \\
\hline$R^{2}$ & 0.29 & & & & 0.30 & & & \\
\hline$F$ & $34.96 *$ & & & & $37.73 *$ & & & \\
\hline
\end{tabular}

Notes: $* P<0.001 ; * * P<0.05 ; * * * P<0.01$.

respectively. Social participation and social trust have a significant impact on both outcome variables including physical activity and nutrition. In our study, we investigated the impact of both structural and cognitive dimensions of social capital on adherence to health lifestyle and underscored the strong correlation between social capital (both structural and cognitive) and adherence to healthy lifestyle in patients with CHD.

Living in the same neighborhood does not enable people to have the same stock of social capital. ${ }^{32}$ In fact, the individual is the repository of societal norms and values (cognitive) and uses personal social networks to strengthen social support, social influence, social engagement, and attachment (structural) to access scarce resources. ${ }^{33}$

The complexity of social capital is further stressed by the existence of deep and changeable relations between its subdimensions. ${ }^{34}$ More broadly, structural and cognitive dimensions of social capital underline the importance of accounting for the quantity as well as quality elements of the concepts. ${ }^{35} \mathrm{We}$ examined subject's perceptions of their cognitive and structural social capital, which may provide a crude but adequate substitute for comprehensive observations.

The mechanism linking social capital and adherence remains to be elucidated, but it is possible that high stocks of social capital can promote adherence through providing effective social support networks for the exchange of health-promoting-information, accessing the resources outside the individual's own network, ${ }^{36}$ and creating a meaningful social context that promotes positive psychological states to enhance motivation for self-care and appropriate health service utilization. ${ }^{37}$

Despite controversies in the literature, we considered a multidimensional approach of social capital, using measures of social participation; social relationships networking, social support, social trust, and sense of belonging were designed to mirror previous literature on social capital. ${ }^{25-27,38}$

In our study, social participation and social trust were factors that strongly influenced adherence. Social participation in a meaningful social context may promote positive psychological states to enhance motivation for self-care and healthy behaviors. Social trust could promote the exchange of health information and access to resources outside the individual's own network. Addressing social capital factors such as social support, social participation, and social trust should be a priority to improve adherence among patients with CHD. ${ }^{39,40}$ It may be important to encourage improving the multidimensional social capital rather than focusing on a single subdimension of social capital.

In addition to the social capital variables, marital status and education level were found to be significantly associated with nutrition. Persons with higher education were more likely to have higher cognitive function and better comprehension capability, so they might better understand the necessity of healthy eating behaviors, be more motivated, and adopt desirable healthy eating behaviors more easily. Being single significantly increased the risk of unhealthy eating behaviors compared to being married or cohabiting. These findings are consistent with previous studies showing statistically significant associations between living alone and unhealthy eating behaviors. ${ }^{41,42}$

The study has limitations that should be mentioned. This study used convenience sampling at the outpatient department, where most of the participants paid regular visits to the community health service center, so this research might not be applicable to those who do not make regular hospital visits. The scales used to measure the social capital (social participation, social networking, social support, social trust, and sense of belonging) were newly developed specifically for this study and therefore warrant the need for further testing the validity and reliability of this instrument in other studies. Given the cross-sectional nature of the study, we cannot deduce causal relationships between social capital and adherence to physical activity and nutrition, but can merely describe probable associations. 


\section{Conclusion}

In conclusion, the main finding of our study - the evidence of effect of social capital on adherence to health behaviors in patients with CHD in Shanghai, China, - suggests that future research on adherence should include the social capital to achieve a more complete understanding of this complex phenomenon on the adherence to the therapies of patients with CHD. Although the underlying path for this particular association remains elusive and the direction of causality cannot be established firmly with the present study design, we believe that community interventionists could use such information, for instance, to improve social participation, social networking, social support, social trust, and sense of belonging toward the community to improve adherence to long-term therapies among the patients with CHD.

\section{Disclosure}

The authors report no conflicts of interest in this work.

\section{References}

1. Lozano R, Naghavi M, Foreman K, et al. Global and regional mortality from 235 causes of death for 20 age groups in 1990 and 2010: a systematic analysis for the Global Burden of Disease Study 2010. Lancet. 2012;380(9859):2095-2128.

2. Liu J, Liu Y, Wang L, et al. The disease burden of cardiovascular and circulatory diseases in China, 1990 and 2010. Chi J Prev Med. 2015; 49(4):315-320.

3. Fuster V. Global burden of cardiovascular disease: time to implement feasible strategies and to monitor results. J Am Coll Cardiol. 2014; $64: 520-522$.

4. National Heart Foundation of Australia. Improving Adherence in Cardiovascular Care. A Toolkit for Health Professionals. Australia: National Heart Foundation of Australia; 2011.

5. Sabate E. Adherence to Long-Term Therapies: Evidence for Action. Geneva, Switzerland: World Health Organization; 2003.

6. Kumbhani DJ, Steg PG, Cannon CP, et al. Adherence to secondary prevention medications and four year outcomes in outpatients with atherosclerosis. Am J Med. 2013;126:693.e1-700.e1.

7. Bhatt DL, Eagle KA, Ohman EM, et al. Comparative determinants of 4-year cardiovascular event rates in stable outpatients at risk of or with atherothrombosis. JAMA. 2010;304:1350-1357.

8. King DE, Mainous AG 3rd, Carnemolla M, Everett CJ. Adherence to healthy lifestyle habits in US adults, 1988-2006. Am J Med. 2009; 122(6):528-534.

9. Platt I, Green HJ, Jayasinghe R, Morrissey SA. Understanding adherence in patients with coronary heart disease: illness representations and readiness to engage in healthy behaviours. Aust Psychol. 2014;2: $127-137$.

10. Wannamethee SG, Shaper AG, Walker M. Physical activity and mortality in older men with diagnosed coronary heart disease. Circulation. 2000;102:1358-1363.

11. Lv J, Yu C, Guo Y, et al. Adherence to healthy lifestyle and cardiovascular diseases in the Chinese population. J Am Coll Cardiol. 2017; 69(9):1116-1125.

12. Ricardo AC, Madero M, Yang W, et al. Adherence to a healthy lifestyle and all-cause mortality in CKD. Clin J Am Soc Nephrol. 2013;8: 602-609.
13. Long JA, Field S, Armstrong K, Chang VW, Metlay JP. Social capital and glucose control. J Commun Health. 2010;35:519-526.

14. Pentecost C, Taket A. Understanding exercise uptake and adherence for people with chronic conditions: a new model demonstrating the importance of exercise identity, benefits of attending and support. Health Educ Res. 2011;26(5):908-922.

15. Wu JR, Moser DK, Chung ML, Lennie TA. Predictors of medication adherence using a multidimensional adherence model in patients with heart failure. J Card Fail. 2008;14(7):603-614.

16. Trivedi RB, Bryson CL, Udris E, Au DH. The influence of informal caregivers on adherence in COPD patients. Behav Med. 2012;44(1): 66-72.

17. Putnam R. Bowling Alone: The Collapse and Revival of American Community. New York, NY: Simon \& Schuster; 2000.

18. Putnam R. Making Democracy Work: Civic Traditions in Modern Italy. Princeton, NJ: Princeton University Press; 1993.

19. Islam MK, Merlo J, Kawachi I, Lindstrom M, Gerdtham UG. Social capital and health: does egalitarianism matter? A literature review. Int $J$ Equity Health. 2006;5:3.

20. Harpham T. The measurement of community social capital through surveys. In: Kawachi I, Subramanian SV, Kim DJ, editors. Social Capital and Health. New York, NY: Springer; 2008:51-62.

21. Krishna A, Shrader E. Cross-cultural measures of social capital: a tool and results from India and Panama. In Social Capital Initiative Working Paper No. 21. Washington, DC: World Bank; 2000.

22. Kawachi I. Commentary: social capital and health: making the connections one step at a time. Int J Epidemiol. 2006;35:989-993.

23. Szreter S, Woolcock M. Health by association? Social capital, social theory, and the political economy of public health. Int J Epidemiol. 2004;33:650-667.

24. Macinko J, Starfield B. The utility of social capital in research on health determinants. Milbank Q. 2001;79:387-427.

25. Berry H, Rickwood D. Measuring social capital at the individual level: personal social capital, values, and psychological distress. Int J Ment Health Promot. 2000;2(3):35-44.

26. Berry H. Social capital and mental health among Aboriginal Australians, New Australians and Other Australians living in a coastal region. Austr E J Adv Mental Health. 2009;8(2):142-154.

27. Stone W. Measuring social capital: towards a theoretically informed measurement framework for researching social capital in family and community life. Aust Inst Family Stud. 2001;24:1-35.

28. Hamano T, Fujisawa Y, Ishida Y, Subramanian SV, Kawachi I, Shiwaku K. Social capital and mental health in Japan: a multilevel analysis. PLoS One. 2010;5:e13214.

29. Bryant C, Norris D. Measurement of social capital: The Canadian experience. Int Rev Adm Sci. 2002;71:475-492.

30. Fujiwara T, Kawachi I. Social capital and health: a study of adult twins in the U.S. Am J Prev Med. 2008;35(2):139-144.

31. Walker SN, Sechrist KR, Pender NJ. The health-promoting lifestyle profile: development and psychometric characteristics. Nurs Res. 1987; 36(2):76-81.

32. Gatrell AC, Popay J, Thomas C. Mapping the determinants of health inequalities in social space: can Bourdieu help us? Health Place. 2004; 10:245-257.

33. Veenstra G. Social capital, SES and health: an individual-level analysis. Soc Sci Med. 2000;50:619-629.

34. Villalonga-Olives E, Kawachi I. The measurement of bridging social capital in population health research. Health Place. 2015;36:47-56.

35. Nyqvist F, Cattan M. Social capital, mental well-being and loneliness in older people. In Leist AK, Kulmala J, Nyqvist F, editors. Health and Well-Being in Old Age: From Biomedical and Life Course Factors to Policy and Practice. New York, NY: Springer; 2014:277-290.

36. Veenstra G, Luginaah I, Wakefield S, Birch S, Eyles J, Elliott S. Who you know, where you live: social capital, neighbourhood and health. Soc Sci Med. 2005;60:2799-2818.

37. Kawachi I, Kennedy BP, Glass R. Social capital and self-rated health: a contextual analysis. Am J Public Health. 1999;89:1187-1193. 
38. Ryan L, Sales R, Tilki M, Siara B. Social networks, social support and social capital: the experiences of recent Polish migrants in London. Sociology. 2008;42(4):672-690.

39. Park LG, Howie-Esquivel J, Whooley MA, Dracup K. Psychosocial factors and medication adherence among patients with coronary heart disease: a text messaging intervention. Eur J Cardiovasc Nurs. 2015;14(3):264-273.
40. Holt-Lunstad J, Smith TB. Loneliness and social isolation as risk factors for CVD: implications for evidence-based patient care and scientific inquiry. Heart. 2016;102(13):987-989.

41. Hanna KL, Collins PF. Relationship between living alone and food and nutrient intake. Nutr Rev. 2015;73(9):594-611.

42. Porter EJ. Problems with preparing food reported by frail older women living alone at home. Adv Nurs Sci. 2007;30(2):159-174.

\section{Publish your work in this journal}

Patient Preference and Adherence is an international, peer-reviewed, open access journal that focuses on the growing importance of patient preference and adherence throughout the therapeutic continuum. Patient satisfaction, acceptability, quality of life, compliance, persistence and their role in developing new therapeutic modalities and compounds to optimize clinical outcomes for existing disease states are major areas of interest for the journal. This journal has been accepted for indexing on PubMed Central. The manuscript management system is completely online and includes a very quick and fair peer-review system, which is all easy to use. Visit http://www. dovepress.com/testimonials.php to read real quotes from published authors.

\footnotetext{
Submit your manuscript here: http://www.dovepress.com/patient-preference-and-adherence-journal
} 